\title{
Study on the Ownership of Motorized and Non-motorized Vehicles in Suburban Metro Station Areas: A Structural Equation Approach
}

\author{
Haixiao Pan $^{1} \cdot \operatorname{Jing} \mathrm{Li}^{1} \cdot$ Peng Chen ${ }^{2}$
}

Received: 13 November 2015/Revised: 10 April 2016/Accepted: 18 April 2016/Published online: 3 May 2016

(C) The Author(s) 2016. This article is published with open access at Springerlink.com

\begin{abstract}
As Chinese megacities are experiencing a largescale motorization and suburbanization, an ever greater number of households are relocated to suburban towns. The increasing average travel distance surely encourages car growth. China is now the world's largest car consumer, resulting in a series of unforeseen environmental and public health issues. On the other hand, scooters, electric bikes, and motorcycles become attractive options to substitute non-motorized bicycles. The ongoing demographic changes should also be taken in account. China has a rapidly aging population and a higher birth rate following reforms to the one-child policy allowing couples to have a second child. These changes will lead to a dramatic alteration of the household composition in the near future. Under above emerging contexts, this study aims to understand what implies the ownership of motorized and nonmotorized vehicles in suburban metro station areas by means of a structural equation model. The data employed in this study are based on a household survey collected from three neighborhoods in Shanghai suburban metro station areas in 2010. The major findings include: (1) Income is a decisive element in car ownership. Specifically, high-income households have higher propensity to own a car, while middle and poor income families tend to own scooters, electric bikes, motorcycles, or bicycles. (2)
\end{abstract}

Jing Li

602609637@qq.com

1 College of Architecture and Urban Planning, Tongji

University, 1239 Siping Rd., Shanghai 200092, China

2 Department of Urban Design and Planning, University of Washington, Seattle, WA 98195-5740, USA

Editor: Xuesong Zhou
Workplace built environment features or mode preferences are not essential to understanding vehicle ownership in Chinese context. (3) Stem families are more likely to own cars; the presence of a child or a senior family member increases the probability of owning a car by enlarging the household. (4) The results estimated for core family and DINK (couple with no child) family are highly consistent, and these families are less likely to own cars. Therefore, transport policies may focus more on households. Providing safe, pleasant, and efficient pedestrian and bicycle paths for children and seniors may decrease the attractiveness of owning cars.

Keywords Suburban metro station areas - Ownership of motorized and non-motorized vehicles - Built environment - Mode preferences - Family composition . Structural equation model

\section{Introduction}

Following decades of sustained economic growth, in 2009, China became the world's largest consumer market for automobiles. The number of new car passengers in 2013 exceeded 100 million [1]. Vehicle ownership is now stabilized in developed countries. However, the rapid growth of car ownership remains a concern in developing countries. Emissions and pollutants from the transportation sector generate environmental and public health issues, such as increasingly severe congestion and air quality deterioration. During the period of transition, curbing the fast motorization has become a prime national concern in China. An exploration of vehicle growth motivators provides direct answers to mitigate challenges such as climate changes, and offer hints in making transport policies. 
Suburbanization is an engine of global car growth. In China, suburban households have greater incentives to purchase cars than households living in the city center and rural areas. First, a great proportion of suburban residents work in city centers, especially those relocated from the city centers. Those residents commute for a much longer distance than people living in the city center. Regarding rural residents, they are mainly employed locally, since driving hours to work in the city center is not an appealing option to them. Secondly, suburban areas are hosting immigrants. In Shanghai for instance, the resident growth rate in the suburban areas from 2005 to $2012(48.9 \%)$ is roughly 6 times higher than in the city center $(8.1 \%)$. Correspondingly, the building area growth rate $(86.6 \%)$ is nearly 3 times higher than in the city center $(29.2 \%$ ) for the same period. It is also obvious from the municipal travel survey [2] that the car growth rate in suburban areas is faster than in central city, while the public transportation growth rate is inversely proportional [3]. Thirdly, minimum parking requirements are continually increasing in local zoning principles. The newly established neighborhoods provide more parking areas and are built in a relatively low density form, which provides the basis for car purchase.

The main role and function of the urban rail transit is that passengers can reach the city suburbs. It also can shorten the residents travel time, support regional urban system development, relieve the population of city center, and inhibit the excessive development potential of the car. It is advantageous to ecological city and connections between different suburbs [4].

Suburban rail transit system in large cities plays an important role in urban system organization [5]. With the integration of urban expansion space and rail transit as the backbone of high-quality public transport services, the urban spatial structure is beneficial to the sustainable urban development [6]. But rail transit does not ensure the realization of sustainable development spontaneously. Keeping comparative advantage of rail transit mobility in the process of urban development is important [7].

To summarize, suburban households are the most representative population regarding car purchase in urban China. Understanding the motives of households in suburban metro station areas for car purchase contributes to identifying effective policy tools for all populations.

Under the irreversible trend of motorization and suburbanization, the number of bicycles throughout urban China is declining sharply, but is especially evident in megacities such as Beijing and Shanghai. For example, in the 10 years between 2004 and 2014, cycling in Shanghai decreased from 24 to $7 \%$ [8]. Due to their faster speed, commuters now prefer scooters, electric bikes, and motorcycles rather than bicycles.

China has many contextual variations which may contribute to different understandings of vehicle ownership such as a denser population, more mixed land use [9, 10], better transit coverage [10], more bicycle use, a greater percentage of stem families (parents with married children), and higher degrees of car pride [11].

Household composition in China is very different to the typical structure of households in western countries. For example, in China: (1) DINK families are still uncommon; (2) singles and couples are considered as an unstable family composition after certain ages; and (3) family members are less independent in comparison to western societies. The 'household' occupies such a central position in Chinese culture that the unit of analysis for car ownership in China is household rather than individual.

The composition of Chinese households is undergoing unprecedented changes as Chinese population ages rapidly and its one-child policy is relaxed, allowing couples to have a second child. Authorities regard the two-child policy as an effective approach to addressing the negative externalities of an aging society. China is facing a challenge regarding household composition, since more aged people and children may lead to more stem families. Higher incomes and lower debts provide a greater purchasing power to the older population; however, the correlation between household composition and car ownership has not been investigated within a Chinese context.

Most existing research methodology relies on explanatory analysis to investigate factors determining car ownership, where the interrelationships among independent variables are unstated or underestimated. As noted from previous studies, an endogenous relationship exists between mode choice and car ownership, which is explained mostly by self-selection effect. The structural equation model (SEM) is an ideal alternative approach to explore the direct and indirect effects among factors to control the possible bias.

This study attempts to investigate (1) how ownerships of motorized and non-motorized vehicles are correlated with different factors in the Chinese context, and understand (2) how the explanatory factors are interrelated. The following paper is organized as follows. A literature review is presented, followed by a model specification which describes the data, methods, and variable selection. Eventually, modeling results are provided, and limitations and conclusions are discussed.

\section{Literature Review}

\subsection{Methodology}

Prior research has drawn a correlation between ownership of different modes of motorized and non-motorized vehicles to factors of built environments, travel characteristics, 
transport policies, socioeconomic profiles, and mode preferences.

Most of the research used linear regression to analyze vehicle mileage [12-18], logistic regression to mode choice [19-22], negative binomial regression to self-selection [23-25], probit regression on non-work trip generation and vehicle mileage [26, 27], and propensity score matching on neighborhood design and walking trips [28, 29].

The methodology used in this empirical study is structural equation model (SEM). SEM is a type of confirmatory analysis, which is frequently used to adjust endogenous and exogenous relationships through specifying latent variables that are linearly combined with observed factors [30]. Researchers are required to conceptualize a model based on a system of assumed interrelationships in using SEM. Moreover, SEM is capable of accounting the total effects resulting from direct and indirect effects among factors. Each effect indicates a path diagram. As a flexible model, SEM can correlate or separate measurement errors based on the researchers' hypotheses [30]. Simma studied the impacts of spatial structure on car ownership, trips by mode and travel distance, using trip diary and environmental data in Austria [31, 32]. Axhausen applied SEM to causal hypotheses linking car ownership, season ticket ownership, and modal usage [33]. Based on this research, Simma and Axhausen compared interrelationships between car ownership, season tickets and travel. And they found consistent results between models [34]. Applying SEM, Chao Liu made an empirical analysis of the urban form influence on household travel and energy consumption [35]. Paulus applicated SEM to understand neighborhood design impact on travel behavior in British metropolitan [36]. SEM can also be used to show the characteristic of urban form and residential carbon emission of Pearl River Delta (PRD) and to compute the relationship of urban form and residential carbon emission [37]. There are many studies linking the built environment to travel and some of them used structural equation models (SEM) to capture complex interactions among built environment and travel variables [3840].

\subsection{Car Ownership}

How built environment factors are correlated with car ownership is frequently investigated in existing research. Land-use variables within urban and suburban areas can affect car ownership quite differently [41]. Suburban areas have an insufficient population or employment density to operate a cost-effective transit system. As non-motorized modes are not a realistic choice to travel over long distances, giving concerns to safety and mobility issues, driving is the preferred travel mode of suburban residents. Suburbanization therefore encourages car growth and use.
Within the built environment, higher density moderates the increase of car ownership. Due to congestion and parking shortages in city centers, driving is not an optimal choice, while considering movement efficiency. Proximity to transit nodes and distance to central areas can also influence car ownership [42]. While theoretically, motorization could be constrained through planning and engineering modifications, land-use changes could only take place over a long-term period, and adapting land use to control vehicle growth is not considered a cost-effective approach [43].

Many transport policies can have an impact on constraining rates of car ownerships. For example, in Buehler's comparative study between Germany and the United States (U.S.) suggested that built environment and demographic factors have no effect on car ownership but have an impact in making transport policies [44]. This study suggests that the higher rate of car ownership in the U.S. is attributable to the relatively low cost of driving. Similar findings are evidenced by the policies of license auction and parking pricing in Shanghai, Hong Kong, and Singapore [11, 45-47]. In addition, recent car sharing programs have also demonstrated effectiveness in reducing rates of car ownership [48]. In sum, transport policies are more effective in reducing cars than planning strategies.

Of all socioeconomic factors, income is the greatest determinant of car ownership [42, 49-54]. However, as a private car is increasingly becoming a household necessity rather than a luxury product, the power of economic factors in determining household's ability to purchase a car is declining over time [53]. Additionally, household size and the presence of children significantly increase the attractiveness of car ownership [42, 53], while seniors heavily rely on cars for travels in the western countries $[55,56]$. It is also worth noting that mode choice and car ownership are closely related in nature [57], car ownership is determined by self-selection, rather than explained by other observable factors [57, 58].

\subsection{Bicycle Ownership}

Possibly because bicycles are more affordable, a very limited number of studies have investigated bicycle ownership. Within the existing research, for an Asian context, rates of bicycle ownership suggest a positive association with population density in Osaka and Kuala Lumpur [59]. However, in a U.S. context, by gathering samples from six cities, individual factors, the social environment and physical environment are cited as the key determinants of bicycle ownership [60]. More specially, individual preference for cycling, the presence of companions, the provision of off-street bicycle infrastructure, and the perceived popularity of cycling in communities are all positive factors which contribute to a 
higher rate of bicycle ownership [60, 61]. Strategies which promote bicycle ownership include densifying bike lane, improving bicycle accessibility to key destinations, reducing block sizes, and providing a recreational center within close proximity to nearby neighborhoods [61]. In summary, while economic factors and socio-demographic profiles do not appear to significantly influence bicycle purchasing, personal preferences and the social and physical environment are of relative importance.

\subsection{Motorcycle Ownership}

Riding a motorcycle is an alternative mode to driving, which is relatively inexpensive and convenient for private mobility [62]. According to prior research, in developed countries, motorcycle ownership is greatly dependent on a rider's personal characteristics and purchasing cost [63]. But in the developing countries, young people from middle or low income backgrounds living in poor neighborhoods are more likely to own motorcycles [52, 64]. Built environment also has a relevant effect on motorcycle ownership. For instance, population density, distance to workplaces, travel time, and transit accessibility all show negative associations with motorcycle ownership [64]. Research conducted so far suggests that the connection between motorcycle ownership and land-use factors are generally weak and income-related factors are related to motorcycle purchasing.

\subsection{Electric Bicycle Ownership}

The popularity of electric bicycles is very specific to China. In other words, the electric bicycle ownership is depending on many contexts. Among the limited research, the popularity of electric bicycles could be explained by economic and political factors [62]. Owning electric bicycles is sensitive to the monetary costs of a vehicle and fuels. Electric bicycles are cheaper in China due to scale economies [62, 65], which greatly improves their affordability for households. In terms of fuel, gasoline is increasingly expensive when compared to electricity. Both factors contribute to the cost-effectiveness of owning electric bicycles. Beyond economic and political factors, land use and bike infrastructure are identified as supportive elements to electric bicycle ownership, such as level of transit services, topography, and intra-regional development differences [62]. Regarding built environments, an empirical study conducted in Zhongshan suggested that land-use features were correlated with electric bicycle ownership [66]. Rural residents rely greatly on electric bicycles. On the contrary, central areas, characterized by higher population density, more mixed land use, greater road connectivity, and better access to workplaces or shopping areas, are associated with a smaller amount of electric bicycle ownerships [66].

In summary, while the choice of residential location, travel characteristics, mode preferences, socio-demographic profiles, and built environment features are all correlated to vehicle ownership, economic factors remain the greatest determinant when choosing the type of vehicle to purchase. By following an agreed conceptual framework to model vehicle ownership, this research attempts to (1) understand vehicle ownership in a Chinese megacity's context, which could be a representative example for the other developing countries; (2) model different types of vehicle ownerships simultaneously through conducting a confirmatory analysis; and (3) investigate the role of family composition in explaining vehicle ownership.

\section{Methodology}

\subsection{Data}

The data were gathered by a household travel behavior survey conducted in the three suburban sub-districts in Shanghai in 2010, named Gongfuxincun, Xinzhuang, and Jiuting as shown in Fig. 1. The survey produced a sample of 2840 individuals from 1000 households. The respondents fall under three categories: workers, unemployed, and children. This research focuses on the relationship of vehicle ownership with family composition, and their household member's workplace built environment, which narrows the sample selected for modeling down to 1,467 employees from 847 households.

\subsection{Variable Selection}

This section describes the variable selection. As previously mentioned, the socio-demographic profiles, income, workplace built environment features, and mode preferences are confronted with family composition. The selection is mostly based on a collinearity test.

This study categorizes motorized and non-motorized vehicles into passenger cars, bicycles, scooters, electric bicycles, and motorcycles. As scooters, electric bicycles, and motorcycles all have similar traveling speeds and monetary costs, they are all merged into one category, labeled "E-bike."

Household is the unit of analysis in measuring sociodemographic factors such as household size, and the presence of a child or senior. Four types of family compositions are considered: single family, DINK family, core family, and stem family. 'Single family' with a limited number of observations was excluded due to collinearity in correlation analysis and acted as a type of unstable family 
Fig. 1 Research areas residents' homes

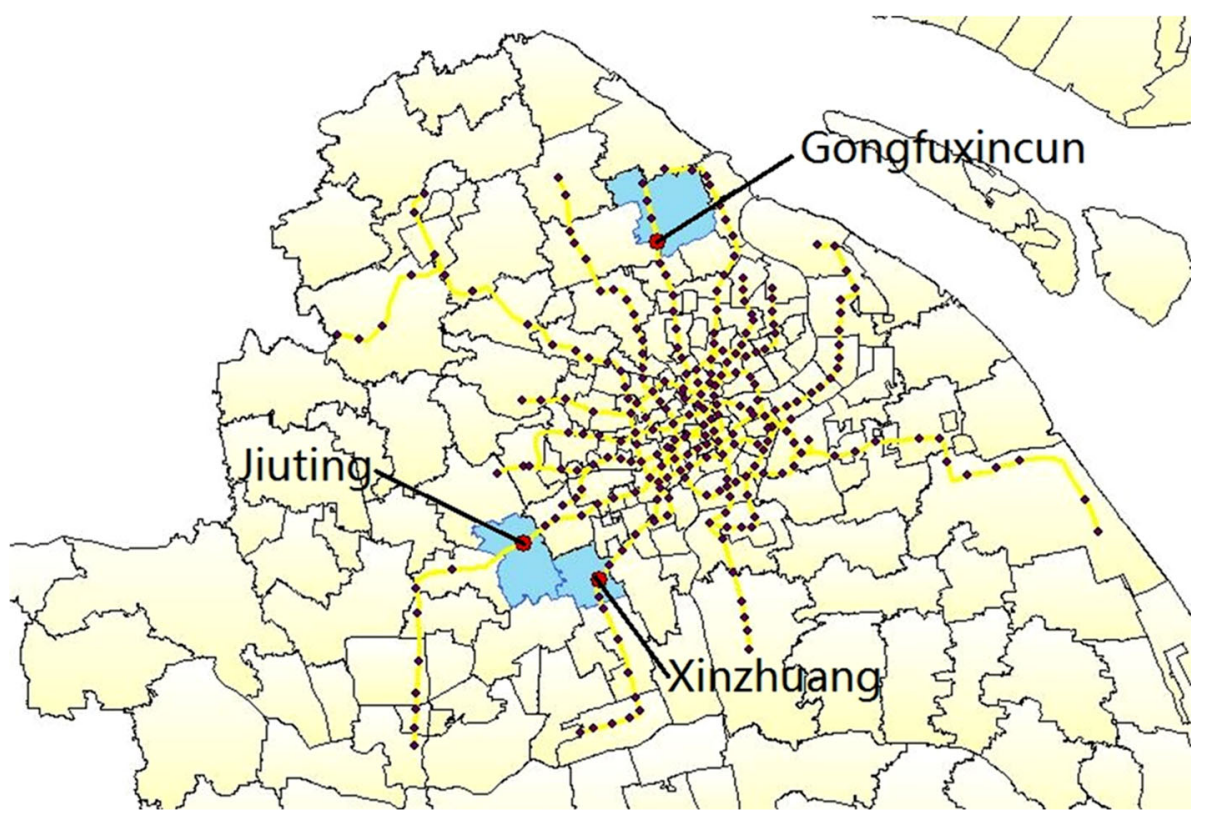

structure. 'Core family' constitutes parents and unmarried children, while 'stem family' refers to a household in which parents and married children are living together. DINK family refers to double income with no kid.

As previously noted, income is a strong determinant of car ownership. In this research, the income variable included is the average income per household member. This variable reflects more accurately the purchasing power of each individual after adjusting to the household size.

Two attitudinal factors regarding mode preferences are included in the model: the intention of riding rail transits and of purchasing a car. The survey investigated households' intention of car purchase. It is worth mentioning that the intention of car purchasing is not identical to car ownership. Attitudinal factors are essential in order to explain the possible bias of the endogenous relationship between car ownership and mode preferences.

Four variables are used to characterize the workplace built environment features: population density, land-use mixture, number of road intersections, and proximity to the closest railway station. The geo-spatial unit that quantifies the built environment features is a $500 \mathrm{~m}$ buffer. Although commuting distance and travel time were also considered to model the travel characteristics, they were later excluded as they did not show any statistical significance. Commuting distance is measured by assuming a shortest path algorithm.

The descriptive analyses for the sixteen factors of the five latent variables are presented in Table 1. The data summary for the socioeconomic factors shows consistent results with the Shanghai averages, verifying the representativeness of the sample. The average household size in the sample is 3.220 , which is higher than the Shanghai average of 2.700 [67], and indicates that larger households are overrepresented in this sample. The average per capita disposable income in the sample is $31,120 ¥$, almost identical to the Shanghai average of $31,838 ¥$ in 2010 [67]. The percentage of car-owning households is $30.00 \%$ of the sample, which is slightly less than the Shanghai average of $32.79 \%$ in 2010 [67]. Among the different types of households, the percentage of car owned stem families is $43.91 \%$, much greater than that of 28.39 and $18.53 \%$ in core families and DINK families, respectively.

\subsection{Variable Selection}

A stepwise logistic regression analysis is run before establishing the structural equation model. The results shown in Table 2 are consistent with the results of the structural equation model. But the regression analysis cannot analyze a variety of vehicles at the same time when there exists only one dependent variable and it cannot analyze the indirect effects as well. To overcome these disadvantages, the structural equation model is now established.

In this research, a system of relationships is modeled by five latent variables, as shown in Fig. 2. The exo genous variables include socio-demographics, income, and workplace built environment. Mode preference is included as a mediator, while vehicle ownership is a defined endogenous latent variable. The factors of income and built environment are frequently cited as 
Table 1 Variable definitions and data summary of predictors for ownerships of motorized and non-motorized vehicles

\begin{tabular}{|c|c|c|c|c|c|c|}
\hline Latent variable & Factor & Definition and measurement & Mean & SD & Min. & Max. \\
\hline \multirow[t]{6}{*}{ Socio-demographics } & Household size & Number of people per household & 3.220 & 1.089 & 1.000 & 7.000 \\
\hline & Children & $\begin{array}{l}\text { Presence of children in a household, } 1 \text { for yes, } \\
\text { else } 0\end{array}$ & 0.340 & 0.474 & 0.000 & 1.000 \\
\hline & Seniors & $\begin{array}{l}\text { Presence of seniors in a household, } 1 \text { for yes, else } \\
\quad 0\end{array}$ & 0.470 & 0.499 & 0.000 & 1.000 \\
\hline & Core family & Parents with unmarried children, 1 for yes, else 0 & 0.490 & 0.500 & 0.000 & 1.000 \\
\hline & Dink family & Couple with no child, 1 for yes, else 0 & 0.180 & 0.381 & 0.000 & 1.000 \\
\hline & Stem family & Parents with married children, 1 for yes, else 0 & 0.270 & 0.443 & 0.000 & 1.000 \\
\hline \multirow{3}{*}{$\begin{array}{l}\text { Ownership of motorized and non- } \\
\text { motorized vehicles }\end{array}$} & Car & Household car ownership, 1 for yes, else 0 & 0.300 & 0.460 & 0.000 & 1.000 \\
\hline & E-bike & $\begin{array}{l}\text { Household scooter, electric bikes or motorcycle } \\
\text { ownership, } 1 \text { for yes, else } 0\end{array}$ & 0.450 & 0.498 & 0.000 & 1.000 \\
\hline & Bike & Household bike ownership, 1 for yes, else 0 & 0.410 & 0.492 & 0.000 & 1.000 \\
\hline Income & $\begin{array}{l}\text { Avg. per capita } \\
\text { income }\end{array}$ & $\begin{array}{l}\text { Average annual income per person in households, } \\
\text { in } 104 ¥\end{array}$ & 3.112 & 1.737 & 0.333 & 15.500 \\
\hline \multirow[t]{2}{*}{ Mode preference } & Car intention & $\begin{array}{l}\text { Head of household reported intention of car } \\
\text { purchase, } 1 \text { for yes, else } 0\end{array}$ & 0.150 & 0.357 & 0.000 & 1.000 \\
\hline & Rail intention & $\begin{array}{l}\text { Household members' intentions of riding rail } \\
\text { transits, } 1 \text { for yes, else } 0\end{array}$ & 0.690 & 0.464 & 0.000 & 1.000 \\
\hline \multirow{4}{*}{$\begin{array}{l}\text { Workplace built environment } \\
\text { features }\end{array}$} & \# of intersections & Number of intersections in $500 \mathrm{~m}$ buffers & 16.772 & 17.478 & 0.000 & 122.000 \\
\hline & Land-use mix & Degrees of mixed land use in $500 \mathrm{~m}$ buffers & 0.648 & 0.127 & 0.000 & 0.961 \\
\hline & $\begin{array}{l}\text { Population } \\
\text { density }\end{array}$ & Population density, in 103 people per $\mathrm{km}^{2}$ & 17.337 & 14.764 & 0.000 & 75.864 \\
\hline & $\begin{array}{l}\text { Workplace rail } \\
\text { proximity }\end{array}$ & Distance to the closet railway stations, in $\mathrm{km}$ & 1.546 & 1.115 & 0.002 & 8.951 \\
\hline
\end{tabular}

Table 2 The results of stepwise logistic regression analysis

\begin{tabular}{lllllll}
\hline Model & Chi square & df & Sig. & -2 Log likelihood & Cox and Snell $R^{2}$ & Nagelkerke $R^{2}$ \\
\hline Step & 7.219 & 1 & 0.007 & & & \\
Block & 201.100 & 4 & 0.000 & & & \\
Model & 201.100 & 4 & 0.000 & 1599.402 & 0.128 & 0.181 \\
& $\mathrm{~B}$ & S.E & Wald & df & Sig. & Exp(B) \\
(Constant) & -3.728 & 0.298 & 156.404 & 1 & 0.000 & 0.024 \\
Household size & 0.411 & 0.070 & 34.543 & 1 & 0.000 & 1.508 \\
Income & 0.432 & 0.041 & 110.377 & 1 & 0.002 & 1.541 \\
Seniors & 0.441 & 0.145 & 9.303 & 1 & 0.009 & 1.554 \\
Dink family & -0.598 & 0.227 & 6.908 & 1 & 0.000 & 0.550 \\
\hline
\end{tabular}

contributors of vehicle ownership and mode preferences. This research has considered the built environment features in both homes and workplaces. However, due to a possible bias resulting from the spatial cluster sampling in the home locations, only the workplace built environment features are included in the modeling. The socio-demographic profiles include family composition, household size, and the presence of children or seniors in the households. The relationships between family composition and vehicle ownership are the primary research objectives.

\section{Result}

The results are presented in the following three parts. The first part shows the modeling outcome of the confirmatory factor analysis. As shown in Table 3, the second part presents the unidimensionality and reliability of the modeling results. Table 4 exhibits the model fit. Figure 2 and Table 5 present the SEM modeling output, as well as the estimated coefficients for exogenous and endogenous variables, statistical significance, and standardized total effects among the explanatory variables. 


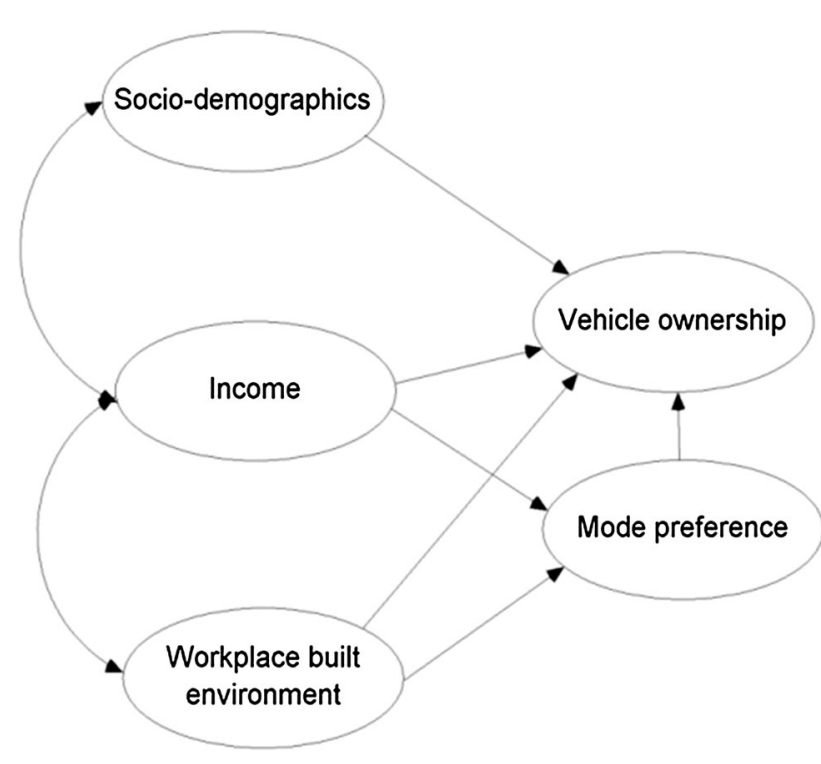

Fig. 2 SEM modeling framework

SEM has several criteria to verify the goodness of fit (GOF). First, if the value of $\chi 2 / \mathrm{DF}$ is smaller than 5.0, the model has a good fit. GFI and CFI values greater than 0.95 suggest a good model fit. As for RMSEA, a model is deemed to be a 'good fit' if a value is less than 0.05; a reasonable range for RMSEA values is between 0.05 and 0.08 ; and RMSEA value larger than 0.1 indicates a poor fit. Table 4 shows the GOF for the SEM model, measured by $\chi 2, \chi 2 / \mathrm{DF}, \mathrm{GFI}, \mathrm{CFI}$, and RMSEA. The number of parameters estimated in this model is 43 , and the degrees of freedom is 93. The Chi square statistic of this model is 427.171. To clarify, the Chi square statistic increases with sample size. Hence, it cannot be an optimal measurement of GOF. However, the other indexes, including GFI, CFI, and RMSEA, indicate that the model fits the data well.

Table 5 shows the effects of socio-demographic factors on the ownerships of motorized and non-motorized vehicles. The standardized total effect of socio-demographic factors is 0.312 . Among different family compositions, the effects of stem status on the ownerships of "car," "Ebike," and "bike" are 0.237, -0.048 , and -0.042 , respectively. However, the effects of core and DINK families on vehicle ownerships are different to that of stem family which is more likely to own cars.

Other socio-demographic profiles such as household size suggest a positive correlation with "car," but negative associations with "E-bike" and "bike." The presence of children or senior citizens in households is positively related to owning a car, while negatively associated with the probability of owning scooters, electric bikes, motorcycles, or bicycles.

This analysis also shows that higher income households are more likely to own cars, but are less likely to purchase scooters, electric bicycles, motorcycles, or bicycles. Furthermore, income is strongly correlated with mode preferences, with higher income households report a greater probability of riding rail transits or planning to purchase cars (Fig. 3).

Built environment features do not appear to correlate with vehicle ownership, but do have an impact on mode preferences. Specifically, employees working in locations of higher population density, greater mixed land use and higher road intersection densities have higher income. These richer people have greater propensities to ride rail transits and plan to purchase cars. Additionally, a longer distance to access railway stations discourages riding rail transits or purchasing cars because their income is relatively low. These conclusions on the intention of riding rail transits are consistent with similar research done in the E.U. and U.S., but differ in terms of intention of car purchasing. These differences are largely due to contextual differences between China, E.U. and U.S. In China, people working in compact developed areas benefit from higher incomes, and as such are more flexible in their choice of home and transportation modes. In addition, most Chinese households only own one car which enables the head of a household to drive, while other members access alternative modes. Wealthier households have the privilege of using cars and rail transit simultaneously [10].

\section{Discussion}

As the key determinant of car ownership, income shows a positive relationship with car purchase [42, 49-54]. A larger household has a higher probability of owning a car [68], in particular when it includes a child or a senior family member [69]. In the western world, seniors have a relatively high reliance on cars $[55,56]$. But in China, it is assumed that senior citizens would financially support their children to own cars, rather than drive by themselves given that retired people in Shanghai have a higher per capita saving $(76,933 ¥)$ than that of employees [67]. Therefore, retired couples (DINK families) are less likely to own cars. Most of the findings of this study are highly consistent with the results of prior research.

Workplace built environment features do not appear to influence vehicle ownership. To highlight the consistency, some existing research shows that population density is not a decision factor of car ownership [43, 70].

Regarding electric bike, Zhang et al.'s research exhibited that built environment features are contributing to its popularity. Yet, similar correlations cannot be confirmed by the data collected and analyzed in suburban metro station areas. It indicates that variations exist between megacities and small cities in China, meaning that 
Table 3 Unstandardized and standardized regression estimates

\begin{tabular}{|c|c|c|c|c|}
\hline & Unstandardized estimate & $P$ value & Standardized estimate & Reliability coefficient \\
\hline \multicolumn{5}{|l|}{ Relationships between latent variables } \\
\hline Mode preference $\leftarrow$ income & 0.017 & 0.000 & 0.385 & \\
\hline Mode preference $\leftarrow$ built environment & -0.039 & 0.002 & -0.318 & \\
\hline Vehicle ownership Income & 0.091 & 0.000 & 0.362 & \\
\hline Vehicle ownership. socio-demographics & 0.135 & 0.000 & 0.312 & \\
\hline Vehicle ownership mode preference & -0.485 & & -0.084 & \\
\hline Vehicle ownership built environment & 0.008 & & 0.012 & \\
\hline Income built environment & 0.000 & & 0.000 & \\
\hline Income socio-demographics & -0.452 & 0.000 & -0.259 & \\
\hline Built socio-demographics & 0.000 & & 0.000 & \\
\hline \multicolumn{5}{|c|}{ Relationships between latent variables and observed factors } \\
\hline Car vehicle ownership & 1.000 & & 0.944 & 0.829 \\
\hline Bike vehicle ownership & -0.216 & 0.000 & -0.191 & 0.036 \\
\hline E-bike vehicle ownership & -0.193 & 0.000 & -0.168 & 0.028 \\
\hline Avg. per capita income income & 1.000 & & 1.000 & 1.000 \\
\hline Car intention mode preference & 1.000 & & 0.211 & 0.045 \\
\hline Rail intention mode preference & 1.769 & 0.001 & 0.287 & 0.084 \\
\hline Workplace rail proximity built environment & 1.000 & & 0.555 & 0.038 \\
\hline Population density built environment & -20.889 & 0.000 & -0.876 & 0.772 \\
\hline Land-use mix built environment & -0.059 & 0.000 & -0.290 & 0.083 \\
\hline \# of intersections built environment & -20.002 & 0.000 & -0.708 & 0.498 \\
\hline Household size socio-demographics & 1.000 & & 0.926 & 0.857 \\
\hline Seniors socio-demographics & 0.280 & 0.000 & 0.566 & 0.320 \\
\hline Children socio-demographics & 0.175 & 0.000 & 0.373 & 0.139 \\
\hline Core family socio-demographics & -0.082 & 0.000 & -0.165 & 0.027 \\
\hline Dink family socio-demographics & -0.220 & 0.000 & -0.582 & 0.338 \\
\hline Stem family socio-demographics & 0.352 & 0.000 & 0.801 & 0.641 \\
\hline \multicolumn{5}{|l|}{ Relationships between error terms } \\
\hline$\varepsilon_{\text {core family }} \leftrightarrow \varepsilon_{\text {dink family }}$ & -0.105 & 0.000 & -0.688 & \\
\hline$\varepsilon_{\text {dink family }} \leftrightarrow \varepsilon_{\text {stem family }}$ & 0.031 & 0.000 & 0.380 & \\
\hline$\varepsilon_{\text {core family }} \leftrightarrow \varepsilon_{\text {stem family }}$ & -0.103 & 0.000 & -0.786 & \\
\hline$\varepsilon_{\text {seniors }} \leftrightarrow \varepsilon_{\text {children }}$ & 0.132 & 0.000 & 0.730 & \\
\hline
\end{tabular}

Table 4 Measures of Fit for SEM

\begin{tabular}{ll}
\hline Number of parameters (NPAR) & 43 \\
Degrees of freedom (DF) & 93 \\
Chi-square goodness of fit test $\left(\chi^{2}\right)$ & 427.171 \\
Relative Chi-square $\left(\chi^{2} / \mathrm{DF}\right)$ & 4.593 \\
Goodness of fit index $(\mathrm{GFI})$ & 0.965 \\
Comparative fit index (CFI) & 0.957 \\
Root mean square approximate error (RMSEA) & 0.050 \\
\hline
\end{tabular}

aforementioned correlations must be considered based on their context. In other words, Shanghai has a dense population and mixed land use across the whole city that is not representative of other Chinese cities. Alternative modes, such as rail transits and buses, are accessible with greater mobility in both urban and suburban areas. In addition, the average travel distance is expected to be much longer in Shanghai; therefore, cycling cannot be an optimal choice in many cases.

\section{Conclusions and Limitations}

This paper has applied a SEM by implementing an analysis to investigate the ownerships of motorized and non-motorized vehicles in suburban metro station areas. Four main conclusions are identified through disentangling the total effects among the workplace built environment features, mode preferences, income, vehicle ownerships, and family composition. (1) Income dominates vehicle ownership. 
Table 5 Total effects calculated for SEM $(\mathrm{N}=1,467)$

\begin{tabular}{|c|c|c|c|c|c|}
\hline \multirow[t]{2}{*}{ Endogenous variables } & \multicolumn{3}{|c|}{ Vehicle ownership } & \multicolumn{2}{|c|}{ Mode preference } \\
\hline & Car & E-bike & Bike & Car intention & Rail intention \\
\hline \multicolumn{6}{|l|}{ Exogenous variables } \\
\hline Socio-demographics & $0.312 * * *$ & & & - & \\
\hline Core family & $-0.049 * * *$ & $0.010 * * *$ & $0.009 * * *$ & - & - \\
\hline Dink family & $-0.171 * * *$ & $0.035 * * *$ & $0.031 * * *$ & - & - \\
\hline Stem family & $0.236 * * *$ & $-0.048 * * *$ & $-0.042 * * *$ & - & - \\
\hline Household size & $0.273 * * *$ & $-0.055^{* * *}$ & $-0.049 * * *$ & - & - \\
\hline Children & $0.110 * * *$ & $-0.022 * * *$ & $-0.020 * * *$ & - & - \\
\hline Seniors & $0.167 * * *$ & $-0.034 * * *$ & $-0.030 * * *$ & - & - \\
\hline Income & $0.362 * * *$ & & & $0.385^{* * *}$ & \\
\hline Avg. per capita income & $0.342 * * *$ & $-0.069 * * *$ & $-0.061 * * *$ & $0.081 * * *$ & $0.110 * * *$ \\
\hline Built Environment & 0.000 & & & $-0.318 * *$ & \\
\hline$\#$ of intersections & 0.000 & 0.000 & 0.000 & $0.048 * *$ & $0.065 * *$ \\
\hline Land-use mix & 0.000 & 0.000 & 0.000 & $0.019 * *$ & $0.026 * *$ \\
\hline Population density & 0.000 & 0.000 & 0.000 & $0.059 * *$ & $0.080 * *$ \\
\hline Workplace rail proximity & 0.000 & 0.000 & 0.000 & $-0.037 * *$ & $-0.051 * *$ \\
\hline
\end{tabular}

0.000 indicates that coefficients are insignificant

Levels of significance: $*<0.05, * *<0.01, * * *<0.001$
Specially, rich households are more likely to have cars, while middle and low income households own scooters, electric bikes, motorcycles, or bikes. (2) Workplace built environment features and mode preferences are not strong determinants of vehicle ownership. (3) Different family compositions have different levels of demand for cars. The presence of a child or a senior citizen in a household contributes to a larger household size and therefore a greater demand for a car. (4) Rates of vehicle ownership among core families and DINK families are highly consistent in comparison to stem families.

To draw policy recommendations, planning programs and engineering approaches cannot effectively curb car growth, however, they could reshape mode preferences. In addition, given the influence of income in determining car purchase, authorities may increase the overall cost of driving through proposing new polices, such as license auction, parking pricing, and vehicle tax. Furthermore, smaller household sizes such as core family and DINK family have lower rates of car purchase. To facilitate their mobility and accessibility, a responsive planning approach would provide more small apartments and restricted parking in neighborhoods with greater transit proximity. The sizes of apartments and zoning principles should be adjusted to the locations. Finally, providing safe, pleasant, and efficient alternative modes and routes for children and seniors may derive less car demand in stem families, such as improving pedestrian and bicycle paths. Although indirectly, these socioeconomic factors contribute to higher rates of household car ownership among stem families. A more sustainable transport system needs to be further investigated with contextual variations to develop measurements and tools to link household composition and car ownership.

Vehicle ownership rate in China remains relatively low compared to that of developed countries. However, continual economic growths, relaxed birth control policy, as well as a forthcoming aging society, all contribute to increasing the number of stem families. In addition, noncommuting trips, such as shopping, entertainment, and recreational trips are attached to household composition and represent an undeniable growth trend. The current transport policies in China emphasize the importance of home-based working trips, while ignoring non-commuting trips and unemployed people. This analysis provides evidence that household composition is essential in deciding vehicle ownerships. Therefore, transport policy should focus on household rather than individuals.

A major limitation in this research is that the data are gathered through spatial cluster sampling. The locationbased selection bias may result in insufficient variations in home built environment features. Hence, home built environment features are excluded from this study. Secondly, as car purchase policy remained stable in Shanghai during the research period, no policy-related indicators are adjusted in this research. Another limitation is that stem families are possibly over represented in the sample. The average household size in the sample is larger than that of the Shanghai average, and bigger households are more likely to be stem families. However, considering that 
Fig. 3 SEM modeling framework

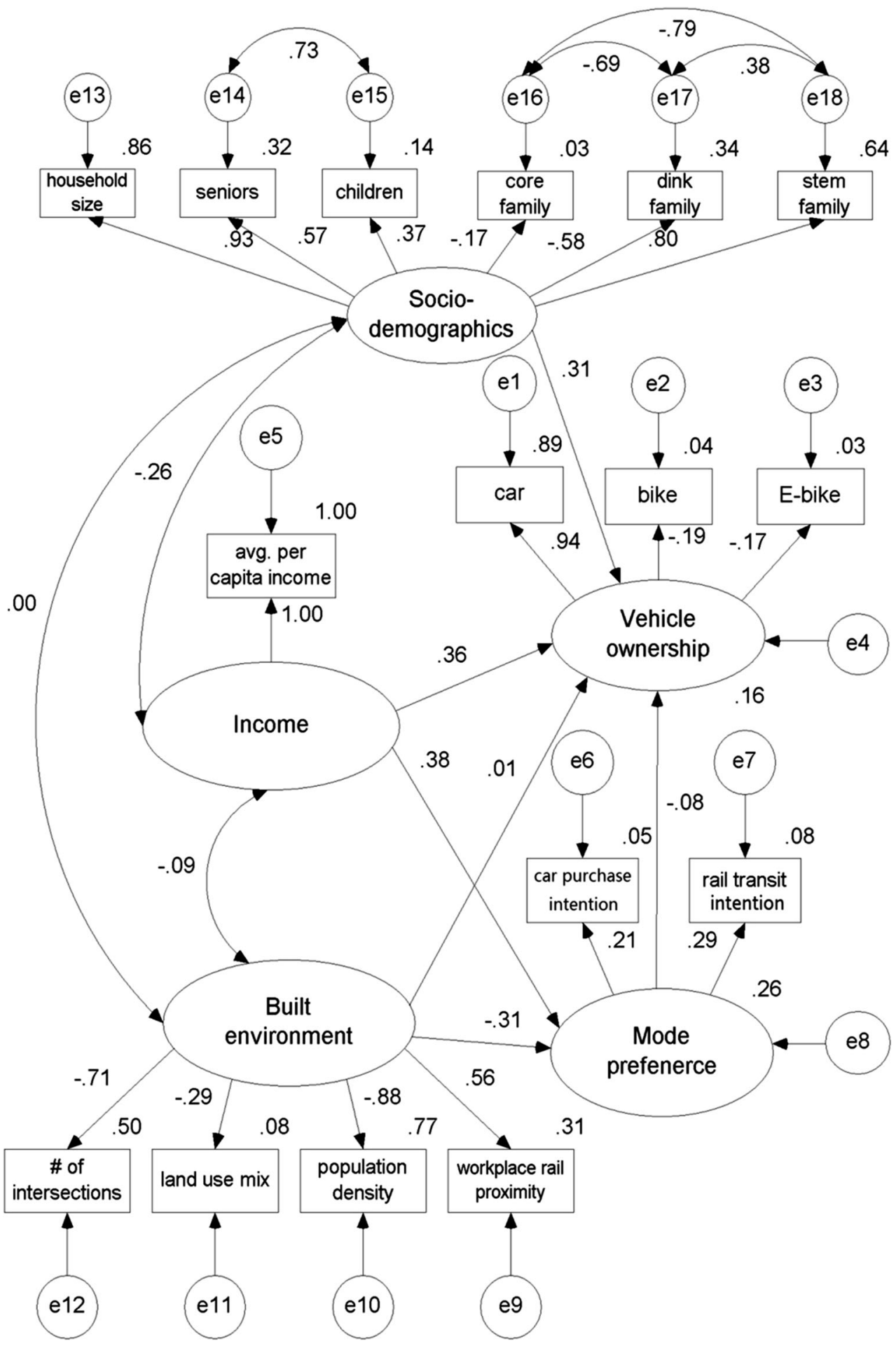

younger and older respondents have more time available to complete the survey, the sampling methodology still needs to be improved in order to produce more accurate results. Finally, the variable intention of purchasing a car is underreported in the data. As noted, $30 \%$ of households in the sample already had private cars, and they are unlikely to respond with intentions to purchase a second car. This may have caused a bias when estimating the residents' transportation mode preferences.

LUM land-use mix entropy is measured by $\mathrm{LUM}=((-1) / \ln n) \Sigma \mathrm{Pi}^{*} \ln \mathrm{Pi}$, 
where $n$ is the number of different land uses in $500 \mathrm{~m}$ buffers and $\mathrm{Pi}$ is the proportion of land in type $\mathrm{i}$. This index is calculated separately for each buffer. The resulting variable LUM is the land-use mix entropy, which varies from 0 to 1 .

Acknowledgments This work was funded by the Natural Science Foundation of China, Grant No. 51478320.

Open Access This article is distributed under the terms of the Creative Commons Attribution 4.0 International License (http://crea tivecommons.org/licenses/by/4.0/), which permits unrestricted use, distribution, and reproduction in any medium, provided you give appropriate credit to the original author(s) and the source, provide a link to the Creative Commons license, and indicate if changes were made.

\section{References}

1. The National Bureau of Statistics of China (2014) China statistical yearbook. China statistics Press, Beijing

2. Municipality, T.a.P.C.o.S. (2012). Shanghai the 4th Comprehensive Transport Survey Summary Report

3. Pan H, Shen Q, Zhao T (2013) Travel and car ownership of residents near new suburban metro stations in Shanghai, China. Transp Res Rec 2394:63-69

4. Qi FJ (2006) Shanghai district rail transit line planning and design concept and application. Urban Rail Transit 11:54-57

5. Pan HM (2002) Metropolitan rapid transit and urban development-the international experience and the research in Shanghai. Tongji University Press, Shanghai

6. Pan HJ (2007) Metropolitan rail transit and the spatial structure optimization. Shanghai Urban Plan 6:37-43

7. Pan HJ (2008) Urban rail transit and the sustainable development. Urban Transp 4:35-39

8. Municipality, T.a.P.C.o.S.(2015). Shanghai the 5th comprehensive transport survey summary report

9. Feng J, Zhou Y, Wu F (2008) New trends of suburbanization in Beijing since 1990: from government-led to market-oriented. Reg Stud 42:83-99

10. Pan H, Zhang M (2008) Rail transit impacts on land use: evidence from Shanghai, China. Transp Res Rec 2048:16-25

11. Chen X, Zhao J (2013) Bidding to drive: car license auction policy in Shanghai and its public acceptance. Transp Policy 27:39-52

12. Bento AM, Cropper ML, Mobarak AM, Vinha K (2003) The impact of urban spatial structure on travel demand in the United States. (World Bank policy research working paper \#3007)

13. Bhatia R (2004) Land use: a key to livable transportation. In: Paper presented at the 40th international making cities livable conference, London, UK

14. Cervero R (2006) Alternative approaches to modeling the traveldemand impacts of smart growth. J Am Plan Assoc 72(3):285-295

15. Cervero R, Duncan M (2006) Which reduces vehicle travel more: jobs-housing balance or retail-housing mixing? J Am Plan Assoc 72(4):475-490

16. Chapman J, Frank L (2004) Integrating travel behavior and urban form data to address transportation and air quality problems in Atlanta, Georgia (Research Project No. 9819, Task Order 97-13). Washington, DC: U.S. Department of Transportation

17. Hess PM, Moudon AV, Snyder MC, Stanilov K (1999) Site design and pedestrian travel. Transp Res Rec 1674:9-19
18. Naess P (2005) Residential location affects travel behavior-but how and why? The case of Copenhagen metropolitan area. Prog Plan 63(1):167-257

19. Cervero R (2002) Built environments and mode choice: toward a normative framework. Transp Res D 7(4):265-284

20. Frank LD, Bradley M, Kavage S, Chapman J, Lawton K (2008) Urban form, travel time, and cost relationships with tour complexity and mode choice. Transportation 35(1):37-54

21. Lee C, Moudon AV (2006) Correlates of walking for transportation or recreation purposes. J Phys Activity Health 3(1):77-98

22. Rodriguez DA, Joo J (2004) The relationship between nonmotorized mode choice and the local physical environment. Transp Res D 9(2):151-173

23. Handy SL, Cao X, Mokhtarian PL (2006) Self-selection in the relationship between the built environment and walking-empirical evidence from Northern California. J Am Plan Assoc 72(1):55-74

24. Khattak AJ, Rodriquez D (2005) Travel behavior in neotraditional neighborhood developments: a case study in USA. Transp Res A 39(6):481-500

25. Shay E, Fan Y, Rodriguez DA, Khattak AJ (2006) Drive or walk? Utilitarian trips within a neo-traditional neighborhood. Transp Res Rec 1985:154-161

26. Boarnet MG, Nesamani KS, Smith CS (2004) Comparing the influence of land use on nonwork trip generation and vehicle distance traveled: An analysis using travel diary data. In: Paper presented at the 83rd annual meeting of the Transportation Research Board, Washington, DC

27. Hedel R, Vance C (2007) Impact of urban form on automobile travel: Disentangling causation from correlation. In: Paper presented at the 86th annual meeting of the Transportation Research Board, Washington, DC

28. Boer R, Zheng Y, Overton A, Ridgeway GK, Cohen DA (2007) Neighborhood design and walking trips in ten U.S. metropolitan areas. Am J Prev Med 32(4):298-304

29. Cao X, Mokhtarian PL, Handy SL (2009) Examining the impacts of residential self selection on travel behaviour: a focus on empirical findings. Transp Rev 29:359-395

30. Golob TF (2003) Structural equation modeling for travel behavior research. Transp Res B 37:1-25

31. Simma A (2000) Verkehrsverhalten als eine Funktion soziodemografischer und r€aumlicher Faktoren. Working Paper 55 , Institute of Transportation, Traffic, Highway- and RailwayEngineering (IVT), Swiss Federal Institute of Technology (ETHZ), Zurich

32. Simma A, Axhausen KW (2001a). Within-household allocation of travel: the case of Upper Austria. In: Presented at the annual meeting of the Transportation Research Board, 7-11 Jan, Washington

33. Axhausen KW, Simma A, Golob TF (2001) Pre-commitment and usage: season tickets, cars and travel. Eur Res Region Sci 11:101-110

34. Simma A, Axhausen KW (2001) Structures of commitment in mode use: a comparison of Switzerland, Germany and Great Britain. Transp Policy 8:279-288

35. Liu C, Shen Q (2011) An empirical analysis of the influence of urban form on household travel and energy consumption. Comput Environ Urban Syst 35(2011):347-357

36. Aditjandra PT, Cao XJ, Mulley C (2011) Understanding neighbourhood design impact on travel behaviour: An application of structural equations model to a British metropolitan data. Transp Res A 46(2012):22-32

37. Yang L (2011) The relationship between urban form and residential carbon emission, a case study in Pearl River Delta. Peking University, Beijing

38. Bagley M, Mokhtarian P (2002) The impact of residential neighborhood type on travel behavior: a structural equations modeling approach. Ann Region Sci 36(2):279-297 
39. Cao X, Mokhtarian PL, Handy SL (2007) Do changes in neighborhood characteristics lead to changes in travel behavior? A structural equations modeling approach. Transportation 34(5): 535-556

40. Cervero R, Murakami J (2010) Effects of built environments on vehicle miles traveled: evidence from 370 U.S. metropolitan areas. Environ Plan A 42(2):400-418

41. Thakuriah P, Liao Y (2005) Analysis of variations in vehicle ownership expenditures. Transp Res Rec 1926:1-9

42. Zegras C (2010) The built environment and motor vehicle ownership and use: evidence from Santiago de Chile. Urban Stud 47:1793-1817

43. Schimek P (1996) Household motor vehicle ownership and use: how much does residential density matter? Transp Res Rec 1552:120-125

44. Buehler R (2011) Determinants of transport mode choice: a comparison of Germany and the USA. J Transp Geogr 19: 644-657

45. Han S, Zhang H, Chen X (2014) Intervention policies for private car ownership in megacities of developing countries. Transp Res Rec 2451:68-76

46. Koh WT (2003) Control of vehicle ownership and market competition: theory and Singapore's experience with the vehicle quota system. Transp Res A 37:749-770

47. Zhang M (2004) The role of land use in travel mode choice: evidence from Boston and Hong Kong. J Am Plan Assoc $70: 344-360$

48. Klincevicius M, Morency C, Trépanier M (2014) Assessing impact of carsharing on household car ownership in Montreal, Quebec, Canada. Transp Res Rec 2416:48-55

49. Chen X, Zhang H (2012) Evaluation of effects of car ownership policies in Chinese megacities. Transp Res Rec 2317:32-39

50. Dargay J, Gately D (1999) Income's effect on car and vehicle ownership, worldwide: 1960-2015. Transp Res A 33:101-138

51. Dargay J, Gately D, Sommer M (2007) Vehicle ownership and income growth, worldwide: 1960-2030. Energy J 28(4):143-170

52. Dargay JM (2001) The effect of income on car ownership: evidence of asymmetry. Transp Res A 35:807-821

53. Gómez-Gélvez J, Obando C (2014) Joint disaggregate modeling of car and motorcycle ownership. Transp Res Rec 2451:149-156

54. Nolan A (2010) A dynamic analysis of household car ownership. Transp Res A 44:446-455

55. Alsnih R, Hensher DA (2003) The mobility and accessibility expectations of seniors in an aging population. Transp Res A 37:903-916

56. Newbold KB, Scott DM, Spinney JEL, Kanaroglou P, Páez A (2005) Travel behavior within Canada's older population: a cohort analysis. J Transp Geogr 13:340-351
57. Pinjari AR, Pendyala RM, Bhat CR, Waddell PA (2011) Modeling the choice continuum: an integrated model of residential location, auto ownership, bicycle ownership, and commute tour mode choice decisions. Transportation 38:933-958

58. Cao X, Xu Z, Fan Y (2009) Exploring the connections among residential location, self-selection, and driving behavior: a case study of Raleigh, NC. In: Paper presented at the 89th annual meeting of the Transportation Research Board

59. Yamamoto $T$ (2009) Comparative analysis of household car, motorcycle and bicycle ownership between Osaka metropolitan area, Japan and Kuala Lumpur, Malaysia. Transportation 36:351-366

60. Handy SL, Xing Y, Buehler TJ (2010) Factors associated with bicycle ownership and use: a study of six small US cities. Transportation 37:967-985

61. Pinjari A, Eluru N, Bhat C, Pendyala R, Spissu E (2008) Joint model of choice of residential neighborhood and bicycle ownership: accounting for self-selection and unobserved heterogeneity. Transp Res Rec 2082:17-26

62. Weinert J, Ma C, Cherry C (2007) The transition to electric bikes in China: history and key reasons for rapid growth. Transportation 34:301-318

63. Burge P, Fox J, Kouwenhoven M, Rohr C, Wigan M (2007) Modeling of motorcycle ownership and commuter usage: a UK study. Transp Res Rec 2031:59-68

64. Anastasopoulos P, Karlaftis M, Haddock J, Mannering F (2012) Household automobile and motorcycle ownership analyzed with random parameters bivariate ordered probit model. Transp Res Rec 2279:12-20

65. Rose G (2012) E-bikes and urban transportation: emerging issues and unresolved questions. Transportation 39:81-96

66. Zhang Y, Li Y, Yang X, Liu Q, Li C (2013) Built environment and household electric bike ownership: insights from Zhongshan metropolitan area, China. Transp Res Rec 2387:102-111

67. Shanghai Municipal Statistics Bureau (2011) Shanghai statistical year book. China Statistics Press, Beijing

68. Maat K, van Wee B, Stead D (2005) Land use and travel behaviour: expected effects from the perspective of utility theory and activity-based theories. Environ Plan 32:33-46

69. Prillwitz J, Harms S, Lanzendorf M (2007) Interactions between residential relocations, life course events, and daily commute distances. Transp Res Rec 2021:64-69

70. Cullinane S (2003) Hong Kong's low car dependence: lessons and prospects. J Transp Geogr 11:25-35 